\title{
San Martín. Una biografía política del libertador
}

Valentín Magi (D) http://orcid.org/0000-0002-4328-6235

Universidad Nacional de Rosario, Argentina

valentinmagi@hotmail.com

Beatriz Bragoni, San Martín. Una biografía política del libertador, Buenos Aires, Edhasa, 2019, 336 páginas.

Beatriz Bragoni se ha consagrado en las últimas décadas como una de las historiadoras argentinas más reconocidas del colectivo que dedica sus investigaciones al siglo XIX. En el marco de su prolífica producción, la historia de San Martín ocupa un lugar destacado. Numerosos artículos, ponencias, capítulos y libros enseñan cuánta atención le ha prestado no solamente al pasado biográfico del héroe sino también a la construcción cultural e historiográfica de esa heroicidad. San Martín. Una biografía política del libertador quizás oficie como un producto coronador y sintetizador de los años que su autora le ha dedicado a la vida del general.

Si bien para quienes acostumbramos a leerla podemos coincidir en que Bragoni ha sido siempre dueña de una pluma a la vez compleja y prolija, en el libro que aquí se reseña, esa cualidad alcanzó una maduración lo suficientemente comprehensiva como para conservar rigurosidad y a la par entonar la narración con miras a que resuene dentro y fuera del espacio académico. Estamos entonces, frente a un tomo que por un largo tiempo se mantendrá como (c) (i) (8) No-Comercial 4.0 Internacional.

Secuencia. E-ISSN 2395-8464 http://secuencia.mora.edu.mx/

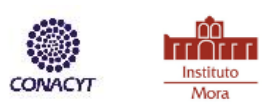


la biografía definitoria del libertador para quienes formamos parte del campo historiográfico sin por esto sugerir la clausura de futuros aportes, revisiones y reelaboraciones- pero que probablemente también ocupe un lugar predilecto en los anaqueles que consulte el gran público.

En este sentido, es dable suponer que la condición historiográfica y editorial de este libro haya sido otorgada no primordialmente por quien lo escribió sino por la colección de Biografías Argentinas que hace años viene impulsando Edhasa. Se han lanzado ya al mercado tomos sobre Alvear, Dorrego, Mitre, Moreno, Rosas, entre otros, elaborados también por historiadores especializados. A casi cuarenta años de iniciado el proceso de normalización universitaria con el retorno de la democracia, la colección hace suponer que la historiografía ha concluido el ciclo de desmitificación de la historia nacional en el que se había sumido durante las décadas de 1980 y 1990. Las viejas hipótesis que corrientes historiográficas de afluentes diversos habían instalado no solo en el campo académico sino en el más vasto campo cultural e intelectual dejan hoy lugar a una disciplina capaz de condensar y sintetizar nuevas perspectivas y miradas lo suficientemente exploradas y complejizadas como para producir narrativas que abarquen la vida toda de sujetos célebres como lo es, en este caso, José de San Martín.

Si bien es cierto que fueron Bartolomé Mitre y Ricardo Rojas quienes entronaron al general en un lugar preeminente al interior del panteón de padres de la patria mediante las figuras del héroe militar y del santo laico, respectivamente, sería cuanto menos injusto y por cierto erróneo sostener que Bragoni discute únicamente con esa doble tradición. Aunque la autora así lo postule, sugiero que esa aseveración resulta insuficiente. En verdad, Bragoni entra en debate con la completa genealogía que traza en el capítulo final, al respecto de los usos 
públicos que se han hecho de la figura del libertador desde la versión mitrista de 1887 hasta el discurso oficial de las presidencias de Cristina Fernández de Kirchner.

Pero si la posición historiográfica de la autora está fundamentalmente dada por la distancia respecto de lo que los campos cultural y político han hecho con la figura de San Martín, en las pocas páginas que integran la introducción, señala que se apega al debate que supone al interior de nuestra disciplina la escritura biográfica, y, según mi lectura, se define al respecto. Para Bragoni, este libro no hubiera sido posible sin el conocimiento previo del contexto histórico que apañó las derivas de la vida de su biografiado. Como lo reconoce explícitamente, postula que sin la revisión de los procesos políticos hispanoamericanos del período de transición entre el mundo colonial y el mundo independiente que se han efectuado durante las últimas décadas, las interpretaciones sobre los acontecimientos que protagonizó San Martín hubieran sido imposibles. Esto no significa que su trayectoria se diluya en las coyunturas en las que se despliega, sino al contrario, que solamente puede ensayarse la rigurosidad histórica sobre la vida de un hombre, cuando previamente el análisis de lo que lo rodea haya resistido a los embates de la contrastación empírica y la discusión historiográfica. El contexto abona la capacidad de interpretación sobre la vida de uno solo más no atenta contra su singularidad, sino que agudiza el análisis sobre esa relación dialéctica.

Hechas estas disquisiciones, se ofrecerá a continuación un recorrido por los capítulos del libro que, valga la advertencia, han sido organizados de acuerdo con la variable del viaje. La autora lo menciona también en la introducción, atravesada por la misma preeminencia otorgada al contexto. La razón que esgrime es la de que el viaje constituye un buen recurso para reflejar la dinámica de la revolución y la guerra, lo que indica coherencia con su propuesta de esbozar una biografía política. De manera que el lector sabe de antemano que se va a encontrar con una historia en la que las variantes a lo largo del tiempo se corresponden con Secuencia. E-ISSN 2395-8464 
desplazamientos espaciales. Las marcas de esta característica quedan a su vez señaladas a lo largo del intenso y extenso aparato erudito que, además de estar compuesto por una profusa bibliografía, lo completan fuentes documentales de archivos situados en Argentina, Chile, Perú, España y Francia.

El primer capítulo corre entre el nacimiento de San Martín en las misiones jesuíticas el 25 de febrero de 1778 y su designación como gobernador de Cuyo en 1814. El viaje que tiene prioridad en el relato es el que realiza desde Londres hacia Buenos Aires, dado que es el disparador para explicar el devenir revolucionario. Tal como la historiografía lo viene subrayando, Bragoni emplaza la clave para entender esa conversión en los acontecimientos desatados en 1808. Son las dificultades políticas y militares que se desatan en la península las que incitan a San Martín a viajar a Londres, donde la Sociedad de Caballeros Racionales prepara su cruce del Atlántico. Pronto, serán sus logros en el campo de batalla en un contexto de debilidad para la dirección porteña de la revolución los que le sugieran trocar la estrategia de defensiva en ofensiva para asegurar la independencia. A tal fin, y por pedido suyo, acabaría siendo designado gobernador de Cuyo.

El segundo capítulo no sale de la "ínsula cuyana”, como lo nombra la autora. Sin embargo, este momento quizás sedentario prepara una salida extrema: cruzar los Andes y liberar Chile y Perú. Son los años políticos de San Martín. Mediante sus decisiones de gobierno, el general enseñó sus prioridades: declarar la independencia y constituir un régimen político centralista -preferentemente monárquico- con escaso margen para el disenso. Agudizando su condición de estratega (que incluía desde propaganda hasta espionaje), el general y gobernador logró que, durante la gestión de Pueyrredón en el directorio, a pesar del momento de carestía, se aunaran todos los esfuerzos para conformar el Ejército de los Andes, sobre el cual Bragoni echará el ojo en los próximos apartados.

Secuencia. E-ISSN 2395-8464 
RESEÑAS

"La campaña a Chile” y "La campaña del Perú” son los títulos de los capítulos tres y cuatro. Es probable que la idea de discontinuidad sea la que mejor resuma la orientación de los acontecimientos durante estos años. Ya en la etapa chilena, San Martín tiene que vérselas con las sinuosas incursiones bélicas que, entre éxitos y fracasos, logran derrotar a los realistas y emplazar a O’Higgins como el Director Supremo del país trasandino. Pero cuando retorna a Mendoza y luego a Buenos Aires, a pesar del recibimiento fervoroso, advierte las complejidades políticas y económicas que pondrán en duda la continuidad de la empresa hacia el Perú. Será únicamente sobre la autoexclusión de los problemas internos que San Martín verá posible su partida hacia Lima, razón por la que firmó su célebre renuncia a la jefatura del ejército.

La incursión peruana terminaría por profundizar las discontinuidades y convertirlas en laberinto, somo sugiere la autora. Luego de zarpar desde Valparaíso previa asistencia financiera de las casas mercantiles inglesas, el general hará gala de lo aprendido durante sus años cuyanos. El tiempo que pasará en el Perú reeditará su doble condición de militar y político, con logros principalmente en el primer plano. Serán sus limitaciones en el segundo, signadas por su profundizado monarquismo y una cierta ceguera sobre las identidades sociopolíticas en conflicto, las que lo terminarán llevando a ceder su centralidad en favor de Simón Bolívar y demás personajes locales.

El capítulo cinco aborda el peregrinaje en el que se sumirá San Martín a su regreso del Perú. Las estaciones de su gira serán: Mendoza-Buenos Aires-El Havre-Londres-BruselasBuenos Aires-París. La razón que explica este itinerario radica en que San Martín se había convertido en una figura desconfiable, tanto para quienes habían hecho la revolución a su lado como para quienes la habían combatido. Es que, en el Río de la Plata había perdido 
reconocimiento político por su renunciamiento en 1820, y en el Viejo Mundo las restauraciones absolutistas lo sospechaban un agente conspirador.

Será el París de la monarquía orleanista la que termine por alojar al general en su “ostracismo voluntario”, título que recibe el capítulo seis. Durante estas páginas, Bragoni se adentra en las intervenciones epistolares que realizará San Martín, en las que se pronunciaría sobre política interna y externa de América, y sobre su trayectoria como militar revolucionario. Aquí el lector se encuentra con un recatado y equilibrado análisis del polémico apoyo que prestó el general al rosismo y de sus cartas a Lafond y a Ramón Castilla que abonarán su reivindicación en clave heroica por parte de las primeras literaturas historiográficas nacionalistas en Argentina.

Los últimos dos capítulos recuperan lo que se hizo de San Martín luego de su muerte: ritos funerarios, estatuas ecuestres, mitificación y mistificación de su figura y legado, usos históricos, historiográficos, políticos y culturales de su nombre entre 1850 y 2015. La fineza de estos últimos apartados demuestra la versatilidad historiadora de Bragoni, capaz de bucear no solo por la historia política del siglo XIX sino por la historia cultural del siglo XX, demostrando cómo y por qué la vida de San Martín trascendió su tiempo y sigue vigente en el nuestro.

Quizás ha sido este último ejercicio el que ha prevenido a la autora de incurrir en anacronismos e ideologismos. Por eso, su San Martín es hoy un magistral ensayo de crítica historiográfica. Su lectura se vuelve impostergable para quienes se interesan sobre la relación entre política, sociedad y cultura durante la historia argentina. 